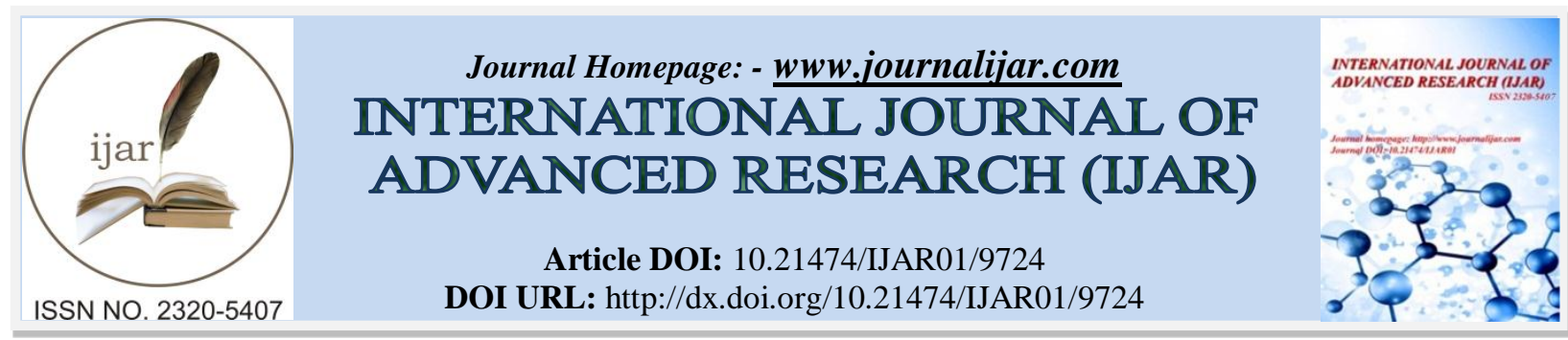

RESEARCH ARTICLE

\title{
THE DEVELOPMENT AND VALIDATION OF AN EGM2008 GEOID MODEL FOR SENEGAL.
}

\author{
Alassane Ba ${ }^{1}$, Ababacar Fall ${ }^{1}$, Papa Babacar Diop Thioune ${ }^{1,2}$ and El Hadji Bamba Diaw ${ }^{1}$. \\ 1. Laboratory of Sciences and Technology of Water and Environment (LaSTEE), Polytechnic School of Thies \\ BPA 10 Thies, Senegal. \\ 2. University Alioune DIOP of Bambey, Higher Institute of Agricultural and Rural Training (ISFAR) PO Box 54, \\ Bambey, Senegal.
}

\section{Manuscript Info}

Manuscript History

Received: 09 July 2019

Final Accepted: 12 August 2019

Published: September 2019

Key words:-

Senegal, EGM2008, GNSS, Orthometric

Height, Ellipsoidal Height.

\begin{abstract}
In Senegal, the use of GPS Global Navigation Satellite Systems (GNSS) technology to give a planimetric position on the WGS84 ellipsoid has increased considerably in recent decades. However, the problem of altitude posed by this technology presents the engineers a complex obstacle, since it is necessary to determine with precision the orthometric position of an object on the surface of the Earth, in particular within the framework of the projects of equipment engineering of the territory or geophysical work. Indeed, a precise determination of the orthometric height obtained most often by leveling is fundamental for a good execution of the projects of civil engineering, public works and territorial development. The use of several altitude reference surfaces (IGN, NGAO, NGS) further complicates the engineers' task thus increasing the risk of costly errors and biases in the conduct of public works and civil engineering. The solution to this problem of precision is the development of a local geoid model for Senegal adapted to the EGM2008 model, which remains a major development in the modeling of Earth's gravity and geoid.
\end{abstract}

Copy Right, IJAR, 2019,. All rights reserved.

\section{Introduction:-}

This study aims to develop and validate an EGM2008 geoid model for Senegal. NASA's EGM2008 is an unparalleled datum of the global gravitational model that is freely available for multiple geodetic and technical applications. It represents a milestone and a new paradigm in the modeling of the global gravitational field, demonstrating for the first time that a single global model can satisfy the requirements of a very wide range of applications (1). The EGM2008 proposes a determination of the geoid with an unprecedented resolution grid of the order of 1 minute of arc or about $1.4 \mathrm{~km}$ formed by the combination of gravimetric data terrestrial, altimetric and gravimetric airborne. EGM2008 is determined with a 2159 degree of order 2159 and contains additional coefficients up to 2190 and order 2159 (2). In areas where densification of points is important, the difference between the geoid undulations and the GPS / level points is about $+/-5 \mathrm{~cm}$ to $+/-58 \mathrm{~cm}(3)$. Since its publication, EGM2008 has become the standard geopotential model used for many applications, including geoid modeling (4).

Corresponding Author:-Alassane Ba. 


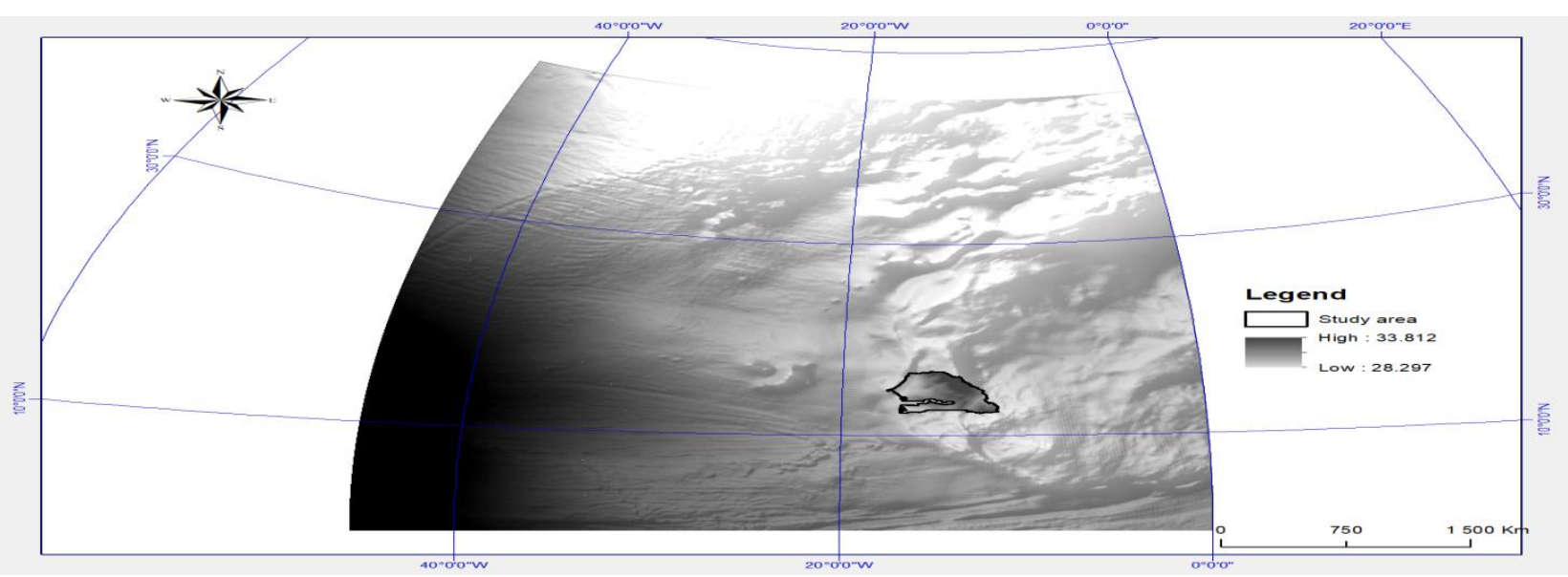

Fig 1:-EGM2008 data and Study area

Availability and free of charge EGM2008 data provide basic solutions for many types of engineering problems around the world especially for developing countries where geodetic modeling technologies are still to be developed. EGM2008 also has significant capital gains value for scientists and engineers working with geospatial analysis. NASA's online product data is easy to download and is also available in an easy-to-use format. However, prior to its use for the determination of orthometric height using GPS, the EGM2008 requires additional regional studies involving site control points and precision verification with direct leveling or gravimetric ground measurement. The study presented in this paper is based on three independent data series: GPS tracking, direct leveling, and determination of geoid ripple from EGM2008.

\section{Material and Methods:- \\ Data}

The data used in this study come from several sources. The data for EGM2008 was provided by NASA through the data sharing site cited above. Using Digital Shadow Radar Topography Mission (SRTM) field data, we extracted the $\mathrm{Z}$ value as a basis for comparison with the other altitude values obtained by leveling and processing the EGM2008 data.

Then, the last set of data is constituted by those from the field campaigns which made it possible to collect a large quantity of measurements (138 points of control and observation spread all over the Senegalese territory) presented in the map above (Figure 2). The geography of these levees highlights a north and east center, a region south of the river, less dense in terms of observations. An imbalance linked to poor national planning turned mainly towards the west of the country which remains the largest demographic basin. Using the ARCGIS 10.5 Geographic Information System software and the Trimble Business Center Topography Software, the results were recorded in a GIS database from which the maps that allowed them to be displayed were taken.

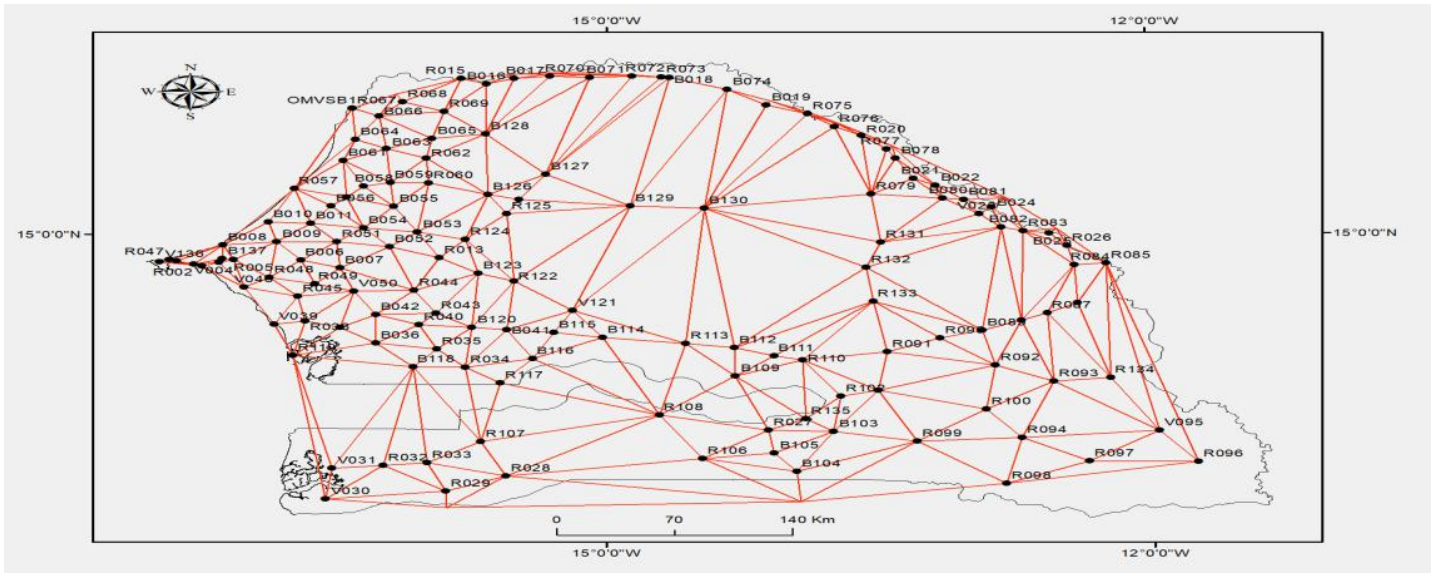

Fig 2:-The GPS/leveling data base over Senegal 


\section{Consideration on altitudes}

The GPS determines the ellipsoidal altitude while the altitude used in engineering work and national geodetic reference systems is the orthometric altitude. The orthometric height we are interested in for this study is the distance along the line of force between the point on the geoid and the point on the Earth's surface (Figure 3).

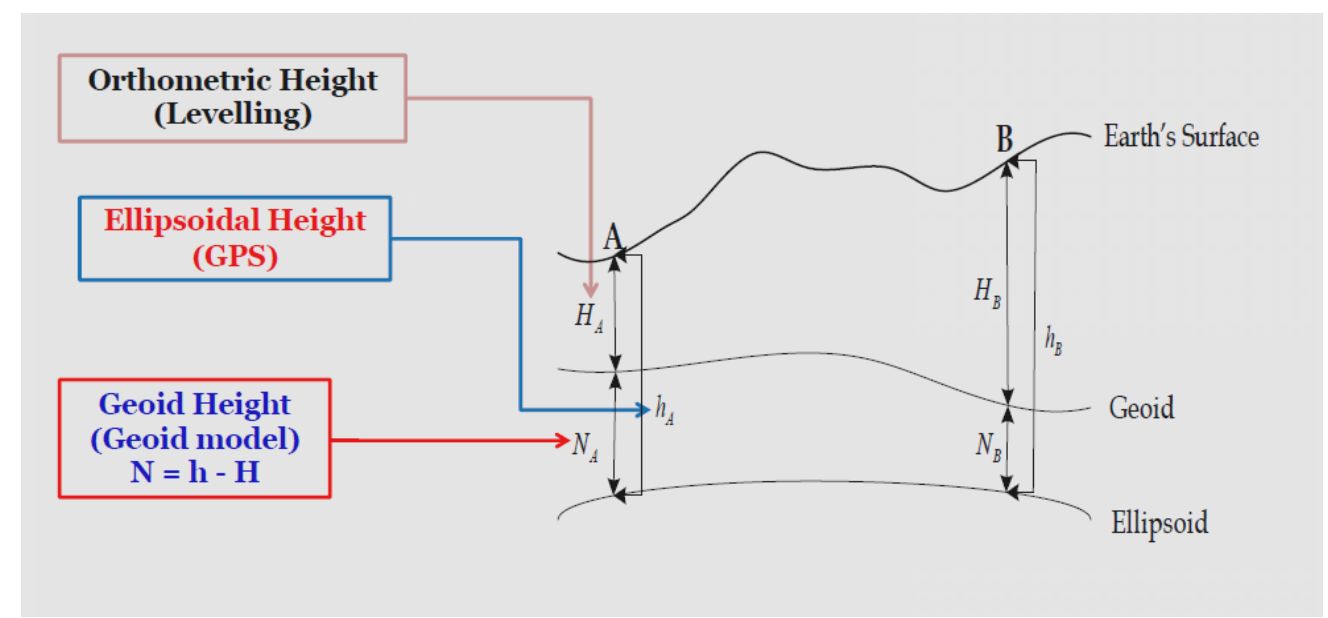

Fig 3 :-Relationship between different altitudes and geoid calculation

The undulation of the geoid $(\mathrm{N})$ is determined here as the difference between the ellipsoidal height $(\mathrm{h})$ and the orthometric height $(\mathrm{H})$. It is represented as being the distance, along the line of force, between the ellipsoid and the geoid.

The following formula is used to determine the orthometric height (6):

$\mathrm{H}($ Orthometric Height $)=\mathrm{h}(\mathrm{GNSS})-\mathrm{N}($ EGM2008)

Which gives for the altitude value of the modeled geoid:

$\mathrm{N}=\mathrm{h}(\mathrm{GNSS})-\mathrm{H}$ (Orthometric Height).

\section{Geoid modeling}

The mathematical and physical concept of the gravity field is based on Newton's law of universal gravitation in 1666.

$$
F=G \frac{M m}{r^{2}}
$$

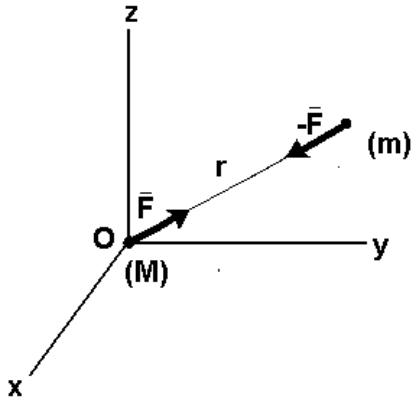

The Newtonian field derives from the potential $U=\frac{G M}{r}$

Potential checks the Laplace equation

$$
\nabla U=\frac{\partial^{2} U}{\partial x^{2}}+\frac{\partial^{2} U}{\partial y^{2}}+\frac{\partial^{2} U}{\partial z^{2}}=0
$$

The solution is obtained in the form of a development in spherical harmonics. 
$U=\frac{G M}{a_{e}} \sum_{n=0}^{\infty}\left(\frac{a_{e}}{r}\right)^{n+1} \sum_{m=0}^{n} P_{n, m}(\sin \varphi)\left(C_{n, m} \cos m \lambda+S_{n, m} \sin m \lambda\right)$

The terms $C_{n, 0}\left(=-J_{n}\right)$ are the Stokes coefficients of the zonal harmonics; The terms $C_{n, m}, S_{n, m}$ are the Stokes coefficients of the tesseral harmonics; The terms $C_{n, n}, S_{n, n}$ are the Stokes coefficients of the sectoral harmonics. Earth's gravitational potential is defined by the development in spherical harmonics as follows [7]:

$$
W(r, \theta, \lambda)=\frac{G M}{r}\left(1+\sum_{n=2}^{\infty}\left(\frac{a}{r}\right)^{n} \sum_{m=0}^{n}\left(C_{n m} \cos m \lambda+S_{n m} \sin m \lambda\right) P_{n m}(\cos \theta)\right)+\Phi
$$

The height of the geoid relative to the reference ellipsoid is obtained by :

$N=\frac{T}{\gamma_{m}}$

The standard presentation of the disturbing potential is expressed by spherical harmonic functions:

$$
T=G M \sum_{n=2}^{\infty} \frac{a_{e}^{n}}{r^{n+1}} \sum_{m=0}^{n} P_{n, m}(\sin \varphi)\left(C_{n, m}^{*} \cos m \lambda+S_{n, m}^{*} \sin m \lambda\right)
$$

The Bruns formula gives the height of the geoid relative to the reference ellipsoid $\mathrm{N}$ as a function of the disturbing potential $\mathrm{T}$ and restores the terrestrial potential.

$$
N=\frac{T}{\gamma}=\frac{G M}{\gamma} \sum_{n=2}^{\infty} \frac{a_{e}^{n}}{r^{n+1}} \sum_{m=0}^{n} P_{n, m}(\sin \varphi)\left(C_{n, m}^{*} \cos m \lambda+S_{n, m}^{*} \sin m \lambda\right)
$$

The data are set as mediate observations and we will express them as functions of unknown parameters. Functional models of observations

$$
\begin{aligned}
& a_{i}=\left(\begin{array}{c}
\cos \left(\varphi_{i}\right) \cos \left(\lambda_{i}\right) \\
\cos \left(\varphi_{i}\right) \sin \left(\lambda_{i}\right) \\
\sin \left(\varphi_{i}\right) \\
\cos \left(\varphi_{i}\right) \sin \left(\varphi_{i}\right) \cos \left(\lambda_{i}\right) / w_{i} \\
\cos \left(\varphi_{i}\right) \sin \left(\varphi_{i}\right) \sin \left(\lambda_{i}\right) / w_{i} \\
\sin \left(\varphi_{i}\right)^{2} / w_{i} \\
1
\end{array}\right) \\
& a_{i}=\left(\begin{array}{c}
a_{i 1} \\
a_{i 2} \\
a_{i 3} \\
a_{i 4} \\
a_{i 5} \\
a_{i 6} \\
1
\end{array}\right) \\
& w_{i}=\sqrt{1-e^{2} \sin \left(\varphi_{i}\right)^{2}} \\
& X=\left(\begin{array}{c}
X 1 \\
X 2 \\
X 3 \\
X 4 \\
X 5 \\
X 6 \\
X 7
\end{array}\right) \\
& \text { og }_{i}^{\text {egm } 2008}=a_{i}^{T} X=F_{i}\left(X_{i}\right)
\end{aligned}
$$

Matrix of observations 
$\mathrm{A}=\left[\begin{array}{ccccccc}a_{i 1} & a_{i 2} & a_{i 3} & a_{i 4} & a_{i 5} & a_{i 6} & 1 \\ \vdots & \vdots & \vdots & \vdots & \vdots & \vdots & \vdots \\ \vdots & \vdots & \vdots & \vdots & \vdots & \vdots & \vdots \\ \vdots & \vdots & \vdots & \vdots & \vdots & \vdots & \vdots \\ a_{n 1} & a_{n 2} & a_{n 3} & a_{n 4} & a_{n 5} & a_{n 6} & 1\end{array}\right]$

Determinations of unknowns by parametric compensation $X=\left(A A^{T}\right)^{-1} A^{T} O G^{e g m 2008}$

$V=\left[\begin{array}{c}\operatorname{og}_{1}^{C a l}-o g_{1}^{e g m 2008} \\ \vdots \\ \vdots \\ o g_{n}^{C a l}-o g_{n}^{e g m 2008}\end{array}\right]$

$\sigma_{0}=\sqrt{\frac{V^{T} V}{n-7}}=58 \mathrm{~cm}$

\section{Results:-}

\section{(Comparing RRS04 data with EGM2008 model)}

The results obtained are represented in the two following figures (FIGS. 4 and 5). First, very high resolution modeling of the local geoid from the EGM2008 data (Figure 4) and field data. Then, the extraction of the altitude values resulting from this modeling of the geoid to compare them with those of the ripple of EGM2008 and to highlight the orthometric height (figure 5). This mathematical modeling updates the orthometric height values of the geoid that vary across our control point field, between $0.7 \mathrm{~m}$ and $182.84 \mathrm{~m}$.

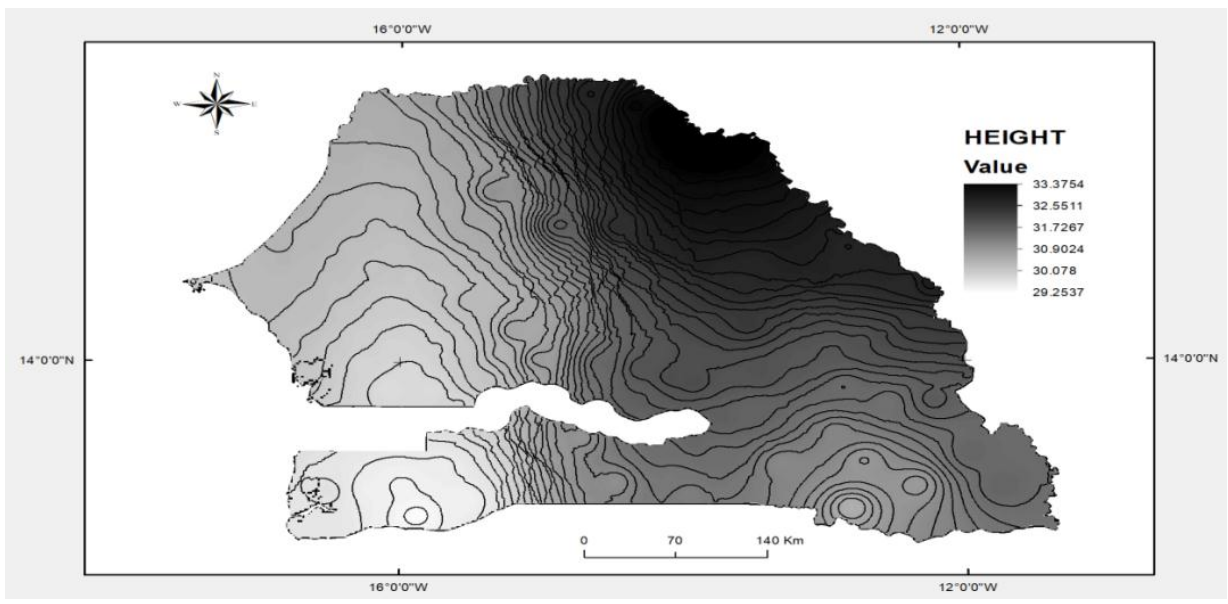

Fig 4:-Geoid modeled on the entire Senegalese territory with a contour of $10 \mathrm{~cm}$.

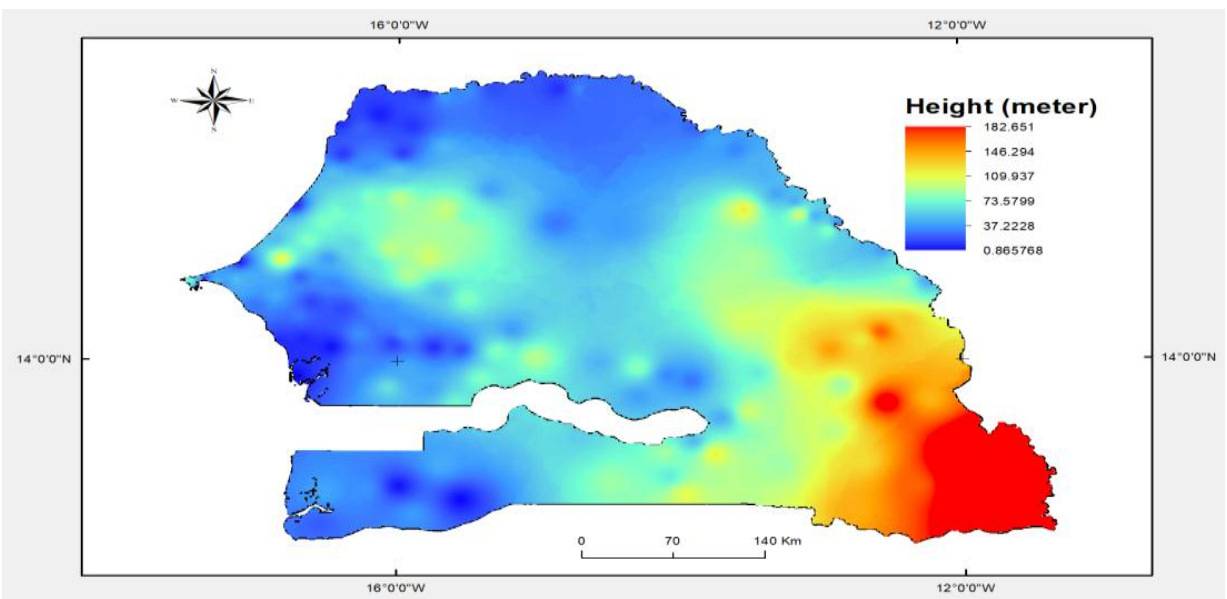

Figure 5: Orthometric Height of geoid modeling 
The standard deviation of the modeled geoid is the lowest $(9.64 \mathrm{~cm})$ as shown by the descriptive statistics in Table 1 which, over the entire series of observations (138), show the maximum altitude and ripple values and as well as averages for comparison. The data obtained with the GPS show values varying between 30,452 $\mathrm{m}$ and $214,337 \mathrm{~m}$.

Table 1:-Statistics on the differences between geoid ripples and orthometric heights and GPS

\begin{tabular}{|l|c|c|c|c|c|c|c|}
\hline & EGM08 & MODEL & Hdem & Hign & GPS & Hegm & Hmodel \\
\hline Nb points & 138 & 138 & 138 & 138 & 138 & 138 & 138 \\
\hline Min (m) & 28.723 & 29.253 & 0.068 & 0.987 & 30.452 & 0.878 & 0.766 \\
\hline Max. (m) & 33.766 & 33.376 & 188.176 & 183.259 & 214.337 & 183.213 & 182.841 \\
\hline Moy. (m) & 30.964 & 30.964 & 33.627 & 30.807 & 61.702 & 30.738 & 30.738 \\
\hline Standard deviation & 0.104 & 0.092 & 2.173 & 2.139 & 2.155 & 2.137 & 2.137 \\
\hline
\end{tabular}

\section{Conclusion:-}

This first high-resolution geoid modeled on Senegal based on the EGM2008 and direct leveling data is thus sufficiently accurate. This approach to improving EGM2008's condition of transforming GPS heights to orthometric heights has proven effective and reproducible across other scales.

Increasing the control points will further refine this model which also validates the accuracy of the EGM2008 data. Our next studies will be oriented to a much more local scale with a higher density of control points.

\section{Bibliography:-}

1. Pavlis, n. K., holmes, s. A., kenyon, s. C., \& factor, j. K., 2012. The development and evaluation of the earth gravitational model 2008 (egm2008), journal of geophysical research: solid earth, 117 (b4), 13-18.

2. Odera, p.a., fukuda, y. And kuroishi, y., 2012. A high-resolution gravimetric geoid model for japan from egm2008 and local gravity data. Earth planets space, vol. 64, no. 5, pp. 361-368, doi: 10.5047/eps.2011.11.004.

3. Griffon-monet a., 2013. La géodésie appliquée aux grands projets d'infrastructures linéaires à l'étranger. Mémoire d'ingénieur, insa de strasbourg. 108p.

4. Ssengendo r., sjöberg l.e., gidudu a., 2011. Evaluation of egm08 in uganda: preliminary results. Conference paper. The first conference on advances in geomatics research.

5. Zahra i., 2016. Détermination de l'exactitude d'un géoïde gravimétrique. Thèse de doctorat en astrophysique [astro-ph]. Psl research university, 2016. Français. <nnt : 2016psleo002〉. <tel-01431701>

6. Sickle j. V., 2008. Gps for land surveyors (3 éd.). California: crc press.

7. Heiskanen, w. A. And moritz, h., 1967. Physical geodesy. W. H. Freeman and company, san francisco. 